\title{
Continuous Wear of Hydrogel Contact Lenses for Therapeutic Use
}

\author{
Daisuke Kudo $^{1}$, Hiroshi Toshida ${ }^{2 \#}$, Toshihiko Ohta ${ }^{2}$, Akira Murakami ${ }^{1}$ \\ ${ }^{1}$ Department of Ophthalmology, Juntendo University School of Medicine, Tokyo, Japan; ${ }^{2}$ Department of Ophthalmology, Juntendo \\ University Shizuoka Hospital, Shizuoka, Japan. \\ Email: "toshida@juntendo.ac.jp
}

Received September $10^{\text {th }}, 2012$; revised October $15^{\text {th }}, 2012$; accepted October $30^{\text {th }}, 2012$

\begin{abstract}
Purpose: To investigate the efficacy and complications of continuous wear of etafilcon A for therapeutic use. Materials and Methods: The subjects were 228 eyes of 219 outpatients prescribed Contact Lens (CL) for one week of continuous therapeutic wear during 10 years. The reason for prescription of CLs, the primary disease, the duration of CL wear and the complications were assessed retrospectively. Results: The predominant reason for prescription of CLs was relief of pain or a foreign-body sensation $(62.3 \%)$ and protection of the corneal epithelium $(20.6 \%)$. The primary disease was post-penetrating keratoplasty $(36.8 \%)$, followed by corneal epithelial erosion $(14.5 \%)$, post-lamellar keratoplasty $(14.0 \%)$ and bullous keratopathy $(12.2 \%)$. The average duration of wearing single lens was $6.5 \pm 3.2$ days. The average duration of wearing CLs in total was $9.2 \pm 10.7$ months. The most frequent problem associated with continuous wear of CLs was their dropping out of CLs (12.3\%). The complications associated with CLs included conjunctivitis with papillary hyperplasia, corneal erosion and superficial punctate keratitis, but corneal ulcer and corneal infiltrates were not found. Conclusion: Serious complications were not shown changing the lenses every week to keep to the prescribed time limit for continuous therapeutic wear, even if corneal epithelial barrier function is impaired.
\end{abstract}

Keywords: Therapeutic Use; Bandage; Soft Contact Lens; Continuous Wear; Complication

\section{Introduction}

Contact Lenses (CLs) are originally developed for the correction of refractive errors. CLs are used not only as an optical device but as a therapeutic device for ocular surface disorders. Recently, Soft Contact Lenses (SCLs) are occasionally used for treating corneal and conjunctival diseases, being used to prevent the exfoliation of corneal epithelial cells and to protect from mechanical damage and to hold wettability of the ocular surface preventing evaporation of the tear fluid [1-13].

In most patients who are prescribed SCLs for therapeutic use, corneal epithelial damage is present and barrier function may be impaired. The corneal epithelium is always in contact with the external environment and is likely to come into contact with foreign bodies and pathogens. Nevertheless, corneal infection usually does not occur in healthy eyes. This may be because of effective corneal epithelial barrier function and protective substances in the tear film. Thus, it is possible that there may be a high

\footnotetext{
*Funding support: None

All authors have no proprietary interest in the materials discussed in this manuscript.

\#Corresponding author.
}

rate of complications associated with continuous use of CLs.

We investigated the efficacy and complications of continuously wearing therapeutic SCLs in patients treated at our hospital over a period of 10 years.

\section{Materials \& Methods}

The subjects were 228 eyes of 219 outpatients who were prescribed etafilcon A hydrogel SCL, Acuvue ${ }^{\mathbb{B}}$ (Johnson \& Johnson, New Brunswick, NJ, USA) for one week of continuous wear at the Department of Ophthalmology of Juntendo University Hospital during the 10 years between March 1995 and March 2005. They included 111 men (116 eyes) and 108 women (112 eyes). All patients provided informed consent, and this study was conducted in accordance with the Declaration of Helsinki. The first trial lens data for eyes with myopia was following; base curve: $8.8 \mathrm{~mm}$; diameter: $14.0 \mathrm{~mm}$, irrespective of average corneal radius. If fitting pattern was too loose, the base curve was changed to $8.4 \mathrm{~mm}$. Eyes with hyperopia were worn plus power lenses, which diameter was 9.1 $\mathrm{mm}$. After checking lens fit, CL wear was started.

The predominant reason for prescription of CLs, the 
predominant primary disease, the duration of wearing therapeutic CLs and the complications associated with CLs were assessed retrospectively. Data were shown as the mean \pm standard deviation.

\section{Results}

Patients included 111 men (116 eyes) and 108 women (112 eyes) and the proportions of male and female patients were comparable. The age of starting to wear CLs was between 8 and 89 years, and their average age was $55.0 \pm 17.2$ years. Base curve of the most frequent prescribed lens was $8.8 \mathrm{~mm}$ (204 eyes), and $8.4 \mathrm{~mm}$ (12 eyes) and $9.1 \mathrm{~mm}$ for hyperopia (12 eyes) were followed.

The predominant reason for prescription of CLs was relief of pain or a foreign-body sensation (142 eyes, $62.3 \%$ ), followed by protection of the corneal epithelium
(47 eyes, $20.6 \%$ ), both of the above (38 eyes, 16.7\%) and protection of the conjunctiva ( 1 eye, $0.4 \%$ ).

The predominant primary disease was post-penetrating keratoplasty ( 84 eyes, 36.8\%), followed by corneal epithelial erosion (33 eyes, 14.5\%), post-lamellar keratoplasty (32 eyes, $14.0 \%$ ), bullous keratopathy (28 eyes, $12.3 \%$ ), corneal ulcer (18 eyes, $7.9 \%$ ), superficial punctate keratitis ( 8 eyes, $3.5 \%$ ) and filamentosa ( 6 eyes, $2.6 \%$ ) (Table 1).The average duration of wearing each single lens was $6.5 \pm 3.2$ days. With regard to the total duration of wearing CLs, the average was $9.2 \pm 10.7$ months. The longest duration was for bullous keratopathy $(14.8 \pm 13.9$ months), followed by penetrating keratoplasty (12.0 \pm 12.0 months) and filamentary keratitis (10.0 \pm 9.2 months) (Table 2).

The most frequent problem associated with continuous

Table 1. The predominant primary diseases for prescription of therapeutic contact lenses (CLs) and major complications.

\begin{tabular}{|c|c|c|c|c|c|}
\hline \multirow{2}{*}{ Predominant primary diseases } & \multirow{2}{*}{ Number of eyes (\%) } & \multicolumn{4}{|c|}{ Major complications (stopped wearing CLs) } \\
\hline & & CLPC & Corneal erosion & SPK & Total \\
\hline Post-penetrating keratoplasty & $84(36.8 \%)$ & $3 / 84(3.6 \%)$ & $1 / 84(1.2 \%)$ & $1 / 84(1.2 \%)$ & $5 / 84(6.0 \%)$ \\
\hline Corneal erosion & $33(14.5 \%)$ & - & - & - & - \\
\hline Post-lamellar keratoplasty & $32(14.0 \%)$ & - & - & - & - \\
\hline Bullous keratopathy & $28(12.3 \%)$ & $7 / 28(25.0 \%)$ & $3 / 28(10.7 \%)$ & $1 / 28(3.6 \%)$ & $11 / 28(39.3 \%)$ \\
\hline Corneal ulcer & $18(7.9 \%)$ & - & - & - & - \\
\hline Superficial punctuate keratitis & $8(3.5 \%)$ & - & - & - & - \\
\hline Filamentosa & $6(2.6 \%)$ & - & - & - & - \\
\hline Others & $19(8.3 \%)$ & - & - & - & - \\
\hline Total & $228(100.0 \%)$ & $10 / 228(4.4 \%)$ & $4 / 228(1.8 \%)$ & $2 / 228(0.9 \%)$ & $16 / 228(7.0 \%)$ \\
\hline
\end{tabular}

Data were collected at the Department of Ophthalmology, Juntendo University Hospital, Japan, between March 1995 and March 2005 . CLPC $=$ contact lens induced papillary conjunctivitis; SPK = Superficial Punctuate Keratitis.

Table 2. Average duration of continuous CL wear and problems associated with the CL wear.

\begin{tabular}{|c|c|c|c|c|c|}
\hline \multirow{2}{*}{ Predominant primary diseases } & \multirow{2}{*}{$\begin{array}{l}\text { Average duration of } \\
\text { wearing (months) }\end{array}$} & \multicolumn{4}{|c|}{ Problems associated with contact lens } \\
\hline & & $\begin{array}{c}\text { Dropping out } \\
\text { of lenses }\end{array}$ & $\begin{array}{c}\text { Lens fitting } \\
\text { failure }\end{array}$ & $\begin{array}{c}\text { Lens } \\
\text { breakage }\end{array}$ & Total \\
\hline Bullous keratopathy $(\mathrm{n}=28)$ & $14.8 \pm 13.9$ & $6 / 28(21.4 \%)$ & - & $1 / 28(3.6 \%)$ & $7 / 28(25.0 \%)$ \\
\hline Post-penetrating keratoplasty $(\mathrm{n}=84)$ & $12.0 \pm 12.0$ & $13 / 84(15.5 \%)$ & $2 / 84(2.4 \%)$ & $1 / 84(1.2 \%)$ & $16 / 84(19.0 \%)$ \\
\hline Filamentosa $(\mathrm{n}=6)$ & $10.0 \pm 9.2$ & $4 / 6(66.7 \%)$ & - & - & $4 / 6(66.7 \%)$ \\
\hline Post-lamellar keratoplasty $(\mathrm{n}=32)$ & $8.4 \pm 7.4$ & - & - & - & - \\
\hline Corneal ulcer $(\mathrm{n}=18)$ & $5.3 \pm 5.3$ & - & $1 / 18(5.6 \%)$ & - & $1 / 18(5.6 \%)$ \\
\hline Superficial punctate keratitis $(\mathrm{n}=8)$ & $2.7 \pm 3.1$ & - & - & - & - \\
\hline Corneal erosion $(n=33)$ & $1.5 \pm 1.8$ & $2 / 33(6.1 \%)$ & - & - & 2/33 (6.1\%) \\
\hline Total $(n=228)$ & $9.2 \pm 10.7$ & 25/228 (11.0\%) & $3 / 228(1.3 \%)$ & $2 / 228(0.9 \%)$ & $30 / 228(13.2 \%)$ \\
\hline
\end{tabular}

Data collected at the Department of Ophthalmology, Juntendo University Hospital, Japan, between March 1995 and March 2005. 
wear of CLs was their dropping out of the lenses from their eyes ( 25 eyes, $11.0 \%$ ), followed by lens fitting failure ( 3 eyes, $1.3 \%$ ) and lens breakage ( 2 eyes, $0.9 \%$ ) (Table 2). All of these problems were reported in patients with bullous keratopathy or penetrating keratoplasty.

Major complications associated with CLs, resulted instop wearing CLs were shown in 16 eyes of 228 eyes (7.0\%), included conjunctivitis with papillary hyperplasia (CLPC) (10 eyes, 4.4\%), corneal erosion (4 eyes, 1.8\%) and superficial punctate keratitis (2 eyes, $0.9 \%$ ) (Table 1 ), but corneal ulcer and corneal infiltrates were not found.

\section{Discussion}

Usually, the use of conventional SCLs for therapeutic wearis reported that it causes few problems.In contrast, there are many evidences of the advantage for therapeutic use of disposable Acuvue ${ }^{\circledR}$ lens clinically [1-6]. Although Acuvue $^{\circledR}$ is a disposable SCL for continuous wear until 1 week, therapeutic use is not permitted by FDA. In general, lens care is not required for continuous wear CLs including therapeutic use of CLs. So the risks of contamination of CLs can be decreased by poor lens cleaning, ineffective lens care agents and contamination of the lens case. It seems to be a favorable situation, but there are actually complications caused by continuous wear of CLs [14-16]. This is because infectious keratit can develop after bacterial infection is established after damage to the corneal epithelium barrier function. Especially corneal epithelium barrier function was usually disturbed in patients who need CLs for therapeutic use. Therefore, it seems that the risk factor is higher than common CL wearers. However, in the present study, even if corneal epithelial barrier function was impaired, serious complications such as infectious keratitis might be avoided if proper care of CLs and the eyes is taken, including changing the lenses every week to keep to the prescribed time limit for continuous wear, periodical eye examinations. Further, the patients understood and agreed attending the eye clinic as soon as an abnormality is noted. However, these can results in health care more expensive depending on the health system of each country. These require spending time and effort. These are drawback.

In the present study, the most frequent problem associated with continuous wear of CLs was their dropping out of the lens mainly shown in patients with bullous keratopathy, post-penetrating keratoplasty and filamentosa (Table 2). These patients were needed a long duration of continuous CL wear. Long period might be a reason of higher frequency of dropping out of their lenses.

The number of the patients who stopped wearing CLs was the highest in that with bullous keratopathy (Table 1). These patients wore CLs temporary until receiving penetrating keratoplasty. That seemed to be the reason.
On the other hand, the patients with bullous keratopathy needed the longest duration of CL wearing. This would be based on the Japanese specific condition, because of lack of donor. Recently, precut donor can be imported from foreign countries for Descemet Stripping Automated Endothelial Keratoplasty (DSAEK), and waiting time for those patients will become shorter, gradually. It may dissolve this problem in Japan.

Recently, it is reported the benefit of silicone hydrogel lenses for therapeutic use [7-13]. On the other hand, the same bacteria were detected from the lens, eyelids and conjunctiva during periodical examination of patients who were continuously wearing silicone hydrogel lenses, suggesting that lens contamination during continuous wear was derived from the eyelids or conjunctiva [17]. Some recent studies have shown that the incidence of infectious keratitis associated with continuous wearing of silicone hydrogel lenses is lower than or similar to that associated with use of daily SCLs or rigid gas permeable contact lenses $[18,19]$. There is a report that, even with silicone hydrogel lenses, continuous wear of CLs is a risk factor for bacterial infection [20]. This problem seemed to have been solved after silicone hydrogel lenses became available, but there may be other reasons why infectious keratitis has not yet been eliminated.

In conclusion, the duration of continuous wear of each Acuvue ${ }^{\circledR}$ lens for therapeutic use is only one week. Because handling of lenses and lens care are not required so that touching the eyes and lenses with contaminated fingers and hands can be avoided, with the result being that there is few possibility of lens contamination by external factors. Especially, most of patients might be sensitive to ocular abnormalities since they already have eye diseases. As mentioned above, it is possible to prevent major complications including infectious keratitis by taking proper care of therapeutic CLs and the eyes, even when continuous wearing of SCLs is done to treat corneal diseases associated with impaired corneal epithelium barrier function. Some drawbacks are still remaining. For example, it results in health care more expensive and requires spending time and effort.

\section{REFERENCES}

[1] P. Donshik, F. J. Weinstock, S. Wechsler, P. Asbell, J. Atwood, H. Davis, B. Farkas, R. L. Farris, E. Gruber and J. Hartstein, "Disposable Hydrogel Contact Lenses for Extended Wear," Contact Lens Association of Ophthalmologists Journal, Vol. 14, No. 4, 1988, pp. 191-194.

[2] J. E. Josephson, B. E. Caffery, I. Campbell and A. R. Slomovic, "Disposable Contact Lenses vs Contact Lens Maintenance for Extended Wear," Contact Lens Association of Ophthalmologists Journal, Vol. 16, No. 3, 1990, pp. 184-188.

[3] K. J. Lindahl, M. D. DePaolis, J. V. Aquavella, G. O. Tem- 
nycky and R. A. Erdey, "Applications of Hydrophilic Disposable Contact Lenses as Therapeutic Bandages," Contact Lens Association of Ophthalmologists Journal, Vol. 17, No. 4, 1991, pp. 241-243.

[4] E. Gruber, "The Acuvue Disposable Contact Lens as a Therapeutic Bandage Lens," Annals of Ophthalmology, Vol. 23, No. 12, 1991, pp. 446-447.

[5] C. S. Bouchard and S. N. Trimble, "Indications and Complications of Therapeutic Disposable Acuvue Contact Lenses," Contact Lens Association of Ophthalmologists Journal, Vol. 22, No. 2, 1996, pp. 106-108.

[6] M. Srur and D. Dattas, "The Use of Disposable Contact Lenses as Therapeutic Lenses," Contact Lens Association of Ophthalmologists Journal, Vol. 23, No. 1, 1997, pp. 4042.

[7] L. Lim, D. T. Tan and W. K. Chan, "Therapeutic Use of Bausch \& Lomb Pure Vision Contact Lenses," Contact Lens Association of Ophthalmologists Journal, Vol. 27, No. 4, 2001, pp. 179-185.

[8] J. Montero, J. Sparholt and R. Mély, "Retrospective Case Series of Therapeutic Applications of a Lotrafilcon a Silicone Hydrogel Soft Contact Lens," Eye \& Contact Lens, Vol. 29, No. 1, 2003, pp. S54-S56. doi:10.1097/00140068-200301001-00015

[9] J. P. Szaflik, A. M. Ambroziak and J. Szaflik "Therapeutic Use of a Lotrafilcon a Silicone Hydrogel Soft Contact Lens as a Bandage after LASEK Surgery," Eye \& Contact Lens, Vol. 30, No. 1, 2004, pp. 59-62. doi:10.1097/01.ICL.0000107181.42704.D8

[10] A. M. Ambroziak, J. P. Szaflik and J. Szaflik, "Therapeutic Use of a Silicone Hydrogel Contact Lens in Selected Clinical Cases," Eye \& Contact Lens, Vol. 30, No. 1, 2004, pp. 63-67. doi:10.1097/01.ICL.0000105563.54932.44

[11] R. Arora, S. Jain, S. Monga, R. Narayanan, U. K. Raina and D. K. Mehta, "Efficacy of Continuous Wear Pure Vision Contact Lenses for Therapeutic Use," Contact Lens \& Anterior Eye, Vol. 27, No. 1, 2004, pp. 39-43. doi:10.1016/j.clae.2003.09.004

[12] C. C. Karlgard, L. W. Jones and C. Moresoli, "Survey of Bandage Lens Use in North America, October-December 2002," Eye \& Contact Lens, Vol. 30, No. 1, 2004, pp. 2530. doi:10.1097/01.ICL.0000105564.71700.EE
[13] Y. Ozkurt, O. Rodop, Y. Oral, A. Cömez, B. Kandemir and O. K. Doğan, "Therapeutic Applications of Lotrafilcon a Silicone Hydrogel Soft Contact Lenses," Eye \& Contact Lens, Vol. 31, No. 6, 2005, pp. 268-269. doi:10.1097/01.ICL.0000163449.92288.71

[14] J. R. Armstrong, K. L. Cohen and L. R. McCarthy, "Haemophilus Influenzae Corneal Ulcer in a Therapeutic Contact Lens Wearer," British Journal of Ophthalmology, Vol. 68, No. 3, 1984, pp. 188-191. doi:10.1136/bjo.68.3.188

[15] S. Koh, N. Maeda, T. Soma, Y. Hori, M. Tsujikawa, H. Watanabe and K. Nishida, "Development of MethicillinResistant Staphylococcus Aureus Keratitis in a Dry Eye Patient with a Therapeutic Contact Lens," Eye \& Contact Lens, Vol. 38, No. 3, 2012, pp. 200-202. doi:10.1097/ICL.0b013e31823ff1f4

[16] N. Inoue, H. Toshida, N. Mamada, N. Kogure and A. Murakami, "Contact Lens-Induced Infectious Keratitis in Japan," Eye \& Contact Lens, Vol. 33, No. 2, 2007, pp. 6569. doi:10.1097/01.icl.0000233869.21964.1b

[17] L. B. Szczotka-Flynn, S. Bajaksouzian, M. R. Jacobs and A. Rimm, "Risk Factors for Contact Lens Bacterial Contamination during Continuous Wear," Optometry \& Vision Science, Vol. 86, No. 11, 2009, pp. 1216-1226. doi:10.1097/OPX.0b013e3181bbca18

[18] F. R. Edmunds, L. C. Timothy and W. T. Reindel, "Cumulative Clinical Results and Projected Incident Rates of Microbial Keratitis with PureVision Silicone Hydrogel Lenses," International Contact Lens Clinic, Vol. 27, No. 5, 2000, pp. 182-186. doi:10.1016/S0892-8967(02)00082-2

[19] T. Sakimoto, Y. Miyamoto, M. Fukuda, Y. Shimomura, K. Takahashi, T. Ishikawa, A. Murakami, K. Nakayasu, S. Takeda, Y. Kamei, M. Matsubara, T. Sakimoto, N. Takaura, N. Fushimi, M. Sawa and Y. Kashima, "ClinicalReport on Long-Term Extended Wear of Silicone Hydrogel Soft Contact Lens (RD-677)," Japanese Journal of Contact Lens Society, Vol. 47, No. 1, 2005, pp. 6-21.

[20] F. Stapleton, L. Keay, K. Edwards, T. Naduvilath, J. K. Dart, G. Brian and B. A. Holden, "The Incidence of Contact Lens-Related Microbial Keratitis in Australia," Ophthalmology, Vol. 115, No. 10, 2008, pp. 1655-1662. doi:10.1016/i.ophtha.2008.04.002 